\title{
ANATOMICAL AND SONOGRAPHIC CORRELATION OF THE FETAL DUCTUS ARTERIOSUS IN FIRST AND SECOND TRIMESTER PREGNANCY
}

\author{
C. Brezinka, ${ }^{\ddagger}$ M. DeRuiter,${ }^{\dagger}$ J. Slomp ${ }^{\dagger}$ N. Den Hollander ${ }^{\ddagger}$ \\ J. W. WladimirofF ${ }^{\ddagger}$ and A. C. GitTENBERGER-DE GROOT ${ }^{\dagger}$ \\ ${ }^{\dagger}$ Department of Anatomy and Embryology, University of Leiden and ${ }^{\ddagger}$ Department of Obstetrics and \\ Gynecology, Academic Hospital Rotterdam-Dijkzigt, Erasmus University, Rotterdam, The Netherlands
}

(Received 4 May 1993; in final form 3 September 1993)

\begin{abstract}
Ultrasonic visualization of the ductus arteriosus in first and second trimester pregnancies was compared with postmortem preparations. Twenty human fetal postmortem specimens from 8 to 19 weeks menstrual age were examined, 11 with microscopic reconstruction, nine with macroscopic dissection. The angle between ductus arteriosus and aortic isthmus (upstream) and ductus arteriosus and descending aorta (downstream) was determined. In 52 normally developing fetuses between 14 and 27 weeks, the angle between the ductus arteriosus and the thoracic spine as visualized in real-time ultrasound was determined. In a further 19 normally developing fetuses between 14 and 25 weeks, ductal blood flow was visualized by colour velocity imaging (CVI). In anatomical preparations, the upstream angle was always less than $90^{\circ}$ and the downstream angle was always $80^{\circ}$ or more. These angles were unrelated to menstrual age. In both real-time and CVI ultrasound, the angle between ductus arteriosus and thoracic spine remained at approximately $90^{\circ}$. CVI showed highest blood flow velocities at the point of ductal insertion into the aorta. When performing Doppler ultrasound examinations in the fetal ductus arteriosus, no menstrual age dependent angle adjustment appears to be necessary.
\end{abstract}

Key Words: Fetal ductus arteriosus, Doppler blood flow velocity waveforms, Colour Doppler, Postmortem studies.

\section{INTRODUCTION}

It has long been established that the intrauterine development of the ductus arteriosus, its embryology and histology, are so unique that it sets this vessel apart from all other cardiac and peripheral fetal vessels (DeRuiter et al. 1989; Clyman et al. 1989; Coceani and Kelsey 1991). Doppler ultrasound studies in the fetal ductus arteriosus have shown that flow velocities in this vessel change in fetal growth retardation (Groenenberg et al. 1989) and during maternal indomethacin administration (Moise et al. 1988).

The ductus arteriosus derives from the left 6th branchial arch, also termed the pulmonary arch artery (Congdon 1922). The ductus arteriosus is a muscular vessel unlike the other branchial arch derivates, which have predominantly elastic walls. The smooth muscle cells in the ductus arteriosus are highly sensitive to prostaglandines and their antagonists (Olley and Co-

Address correspondence to: Prof. Dr. A. C. Gittenberger-de Groot, Dept. of Anatomy and Embryology, University of Leiden, P.O. Box 9602, NL-2300 RC Leiden, The Netherlands. ceani 1987). Another unique feature of the ductus arteriosus is the development of intimal cushions protruding into the lumen. Intrauterine morphological development of the ductus arteriosus prepares for effective closure after birth (Gittenberger-de Groot et al. 1980).

In recent years, it has become possible to observe the fetal ductus with ultrasound and to measure blood flow velocities in this vessel using pulsed wave and continuous wave Doppler (Huhta et al. 1987). We recently applied transvaginal ultrasound to observe ductus arteriosus flow velocities as early as 11 weeks menstrual age (Brezinka et al. 1992). With these advances in ultrasound technology, attempts have been made to correlate ultrasound with the developing vascular anatomy of the normal and the malformed fetus (Allan et al. 1984; Angelini et al. 1988). There is scant and conflicting information as to the changing anatomical relationship between the ductus arteriosus and aorta with advancing gestational age (Odé 1951; Mancini 1951; Roeder 1902). This would have implications for the technique of Doppler flow velocity waveform recording in the ductus arteriosus of the developing fetus. 
Further, in vitro studies would be necessary to clarify the exact anatomic relationship between these two vessels and to relate findings to the in vivo situation as studied by ultrasound.

The following questions were addressed:

1. What is the angle between the ductus arteriosus and aortic isthmus (upstream) and descending aorta (downstream) in vitro; do these angles display an age-dependent change?

2. How do these in vitro observations relate to the in vivo situation as studied by real-time ultrasound and colour velocity imaging?

Attention was focussed on the late first and second trimester of pregnancy, because whilst ductal behaviour in the perinatal period is well documented (Gittenberger de Groot et al. 1980), a systematic study of ductal and aortic relation pertinent to the present clinical diagnostic tools has not been performed in these stages of pregnancy.

\section{MATERIAL AND METHODS}

Several methods were used to obtain a complete picture of the spatial relationship between the ductus arteriosus and the aorta in the first and second trimester of pregnancy. Postmortem investigation was performed on three-dimensional reconstructions of serially sectioned fetuses and on macroscopic preparations of embryos preserved in toto. In vivo observations were obtained from real time ultrasound images of the right cardiac outflow tract from the pulmonary valve to the descending aorta (Reed et al. 1988) and from colour velocity imaging (CVI) visualizations of the same structures (Pesque 1990). CVI makes it possible to differentiate velocities within a given vessel (Huisman and Wladimiroff 1992).

\section{a) 3-D reconstructions of serially sectioned embryos} (Fig. la and $1 b$ )

Eleven fetuses between 9-19 weeks of menstrual age, from the collection of the Leiden Department of Anatomy and Embryology, were studied microscopically. These embryos were serially sectioned at $10 \mu \mathrm{m}$, mounted on glass slides and alternately stained with haematoxylin-eosine, resorcine-fuchsine, a modified van Gieson stain and Azan and Methyl-green pyronine. The fetuses were also examined for abnormalities. One showed stigmata of fixation artefacts and was not included in the present study. To prevent a skewed reconstruction, care was taken to use the oesophagus as a reference structure because it is generally accepted as the second best parallel structure in the absence of the fetal spine. Outer and inner contours of each 10th section of the aortic arch, the pulmonary trunk, the pulmo-
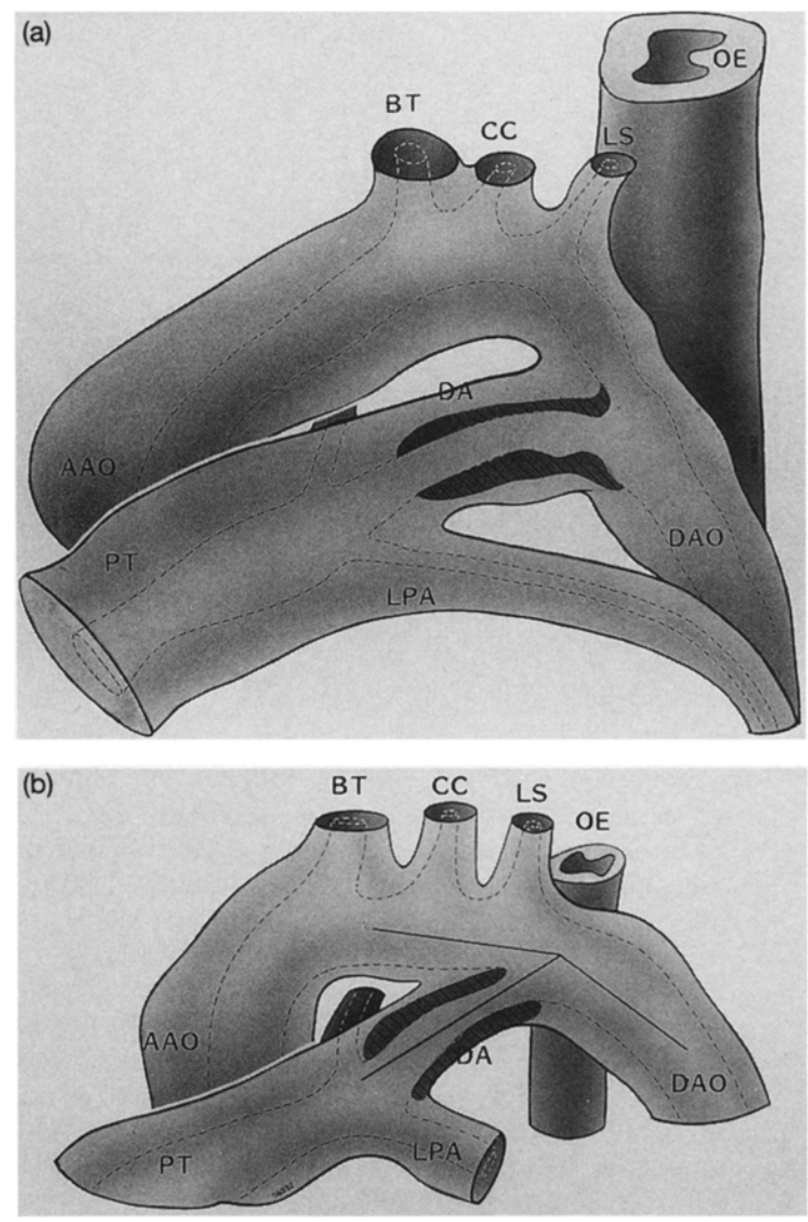

Fig. 1. (a) Graphic reconstruction of a $45 \mathrm{~mm} \mathrm{CRL} \mathrm{(10}$ weeks) embryo with the Ductus Arteriosus (DA) leading horizontally towards the aorta. Ductal tissue is shaded dark. (AAo: ascending aorta, BT: brachiocephalic trunk, CC: common carotid artery, LS: left subclavian artery, PT: pulmonary trunk, LPa: left pulmonary artery, DAo: descending aorta, Oe: oesophagus). (b) Graphic reconstruction of a $120 \mathrm{~mm}$ CRL (16 weeks) fetus with a straight line drawn through the ductus arteriosus (DA). It forms angle a, the "upstream angle" with the line drawn through the aortic arch, and angle b, the "downstream angle," with the line pointing towards the descending aorta (DAo).

nary arteries, the ductus arteriosus and the upper part of the descending aorta were drawn after enlargement, using a Zeiss microscope with a drawing attachment. When it could be discerned, ductal tissue was highlighted. The outside wall and the lumen of the aortic arch and the ductus arteriosus were reconstructed three-dimensionally in an antero-lateral view using the method described by Tinkelenberg (1979).

It was attempted to make angle measurements by drawing a line through the middle of the ductus arteriosus, which at the point of insertion into the aorta would cross with 1) a line going upstream through the aortic isthmus and 2) a line going downstream into the de- 
(a)

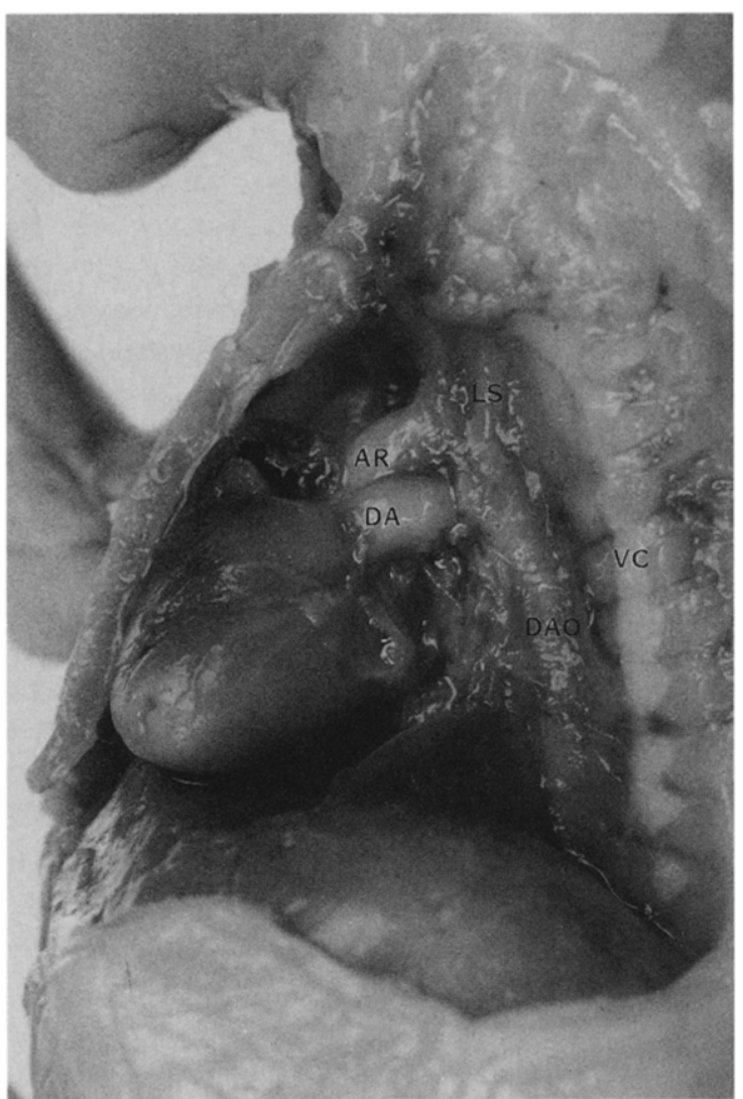

(b)

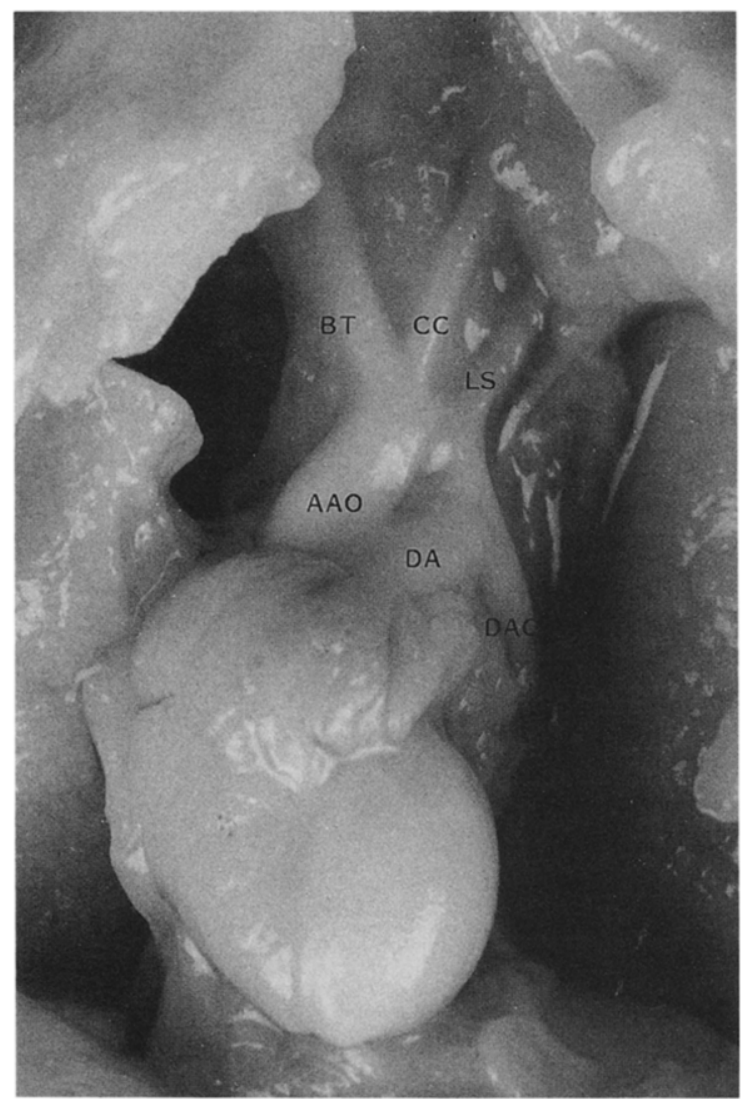

Fig. 2. (a) A fixated $90 \mathrm{~mm} \mathrm{CRL} \mathrm{(13} \mathrm{weeks)} \mathrm{fetus} \mathrm{with} \mathrm{the} \mathrm{left} \mathrm{rib} \mathrm{cage} \mathrm{and} \mathrm{left} \mathrm{lung} \mathrm{and} \mathrm{thymus} \mathrm{removed} \mathrm{to}$ allow an antero-lateral view of the ductus arteriosus (DA) entering the Aorta (DAo) shortly below the left subclavian (LS) artery has branched off the aortic arch (Ar). The descending aorta runs parallel to the vertebral column (VC). (b) An anterior view of a fixated $80 \mathrm{~mm}$ (12 weeks), fetus with the left pulmonary artery and left bronchus severed to enable the view onto the ductus arteriosus (DA). The ascending aorta (AAo) forms the aortic arch giving off the brachiocephalic trunk (BT), the common carotid artery (CC) and the left subclavian artery (LS). This is the view that should be attempted when performing Doppler measurements of the ductus arteriosus.

scending aorta. The centre of the vascular lumen of all vessels was used to place these lines, using the method described by Mancini (1951). Thus two angles, one upstream (angle a) and one downstream (angle b) were obtained (Fig. 1b). The upstream and downstream angles would not necessarily add up to 180 degrees, as in most cases flow direction changes markedly after the insertion of the ductus arteriosus.

\section{b) Macroscopic preparation of fixated fetuses (Fig. $2 a$ and $2 b$ )}

Another nine fetuses between 12-19 weeks menstrual age from the Leiden collection were studied macroscopically. The specimen had been fixed in $4 \%$ phosphate buffered formalin or in Bouin's solution. The thorax was opened, the rib cage of the left side removed, the mediastinum incised and the left lung and the thymus removed to obtain an unobstructed view of the right cardiac outflow tract. The fetuses were subsequently mounted on glass plates in a standardized position permitting the same antero-lateral view on the vessels of interest as had been used for the reconstructions under a) for macro-photography. As in the serially sectioned fetuses, both the upstream and the downstream angle of the ductus arteriosus were determined by drawing lines on the vessels on the photographs. Furthermore, the angle between the ductus arteriosus and the thoracic part of the vertebral column was determined.

c) Ultrasound real-time images of the ductus arteriosus (Fig. $3 a$ and $3 b$ )

In 52 normally developing fetuses from singleton pregnancies between 14 and 27 weeks menstrual age, referred to the Division of Prenatal Diagnosis of the Department of Obstetrics and Gynecology of Rotterdam Erasmus University Hospital for ultrasound screening, an image of the full length of the right car- 


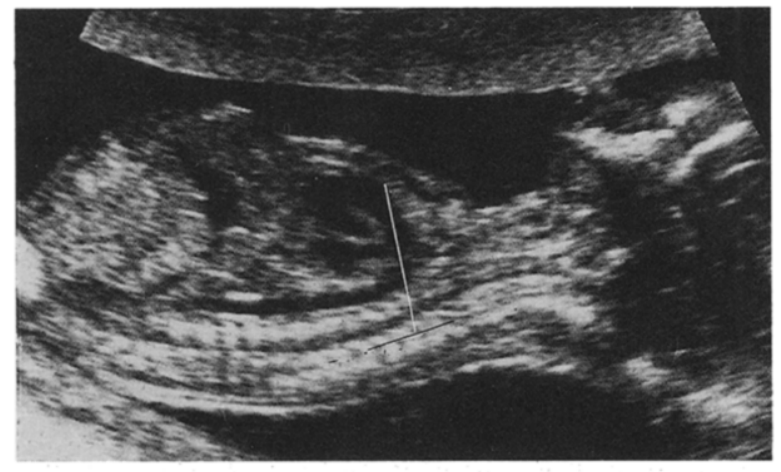

17 wk

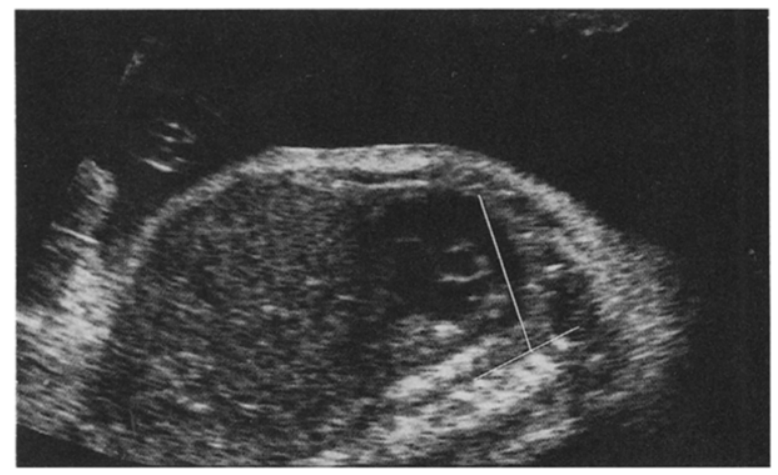

25 wk

Fig. 3. View of the right cardiac outflow tract in a healthy fetus at 17 (top) and 25 weeks of gestation (bottom). Lines are drawn through the ductus arteriosus where it follows an approximately longitudinal course. A second line is drawn through the thoracic part of the vertebral column. In fetal apnea, an angle between $85^{\circ}$ and $115^{\circ}$ (mean 93.) was observed.

diac outflow tract from the right ventricle through the pulmonary trunk and the ductus arteriosus into the descending aorta was obtained, using a Toshiba 270 realtime scanner with a $3.75 \mathrm{MHz}$ abdominal probe. Because the aortic arch is situated in a more oblique and dorsal plane compared with the sagittal plane of the right cardiac outflow tract, it was not possible to simultaneously visualize the two structures on ultrasound and thus measure upstream angles in vivo. Images were obtained during fetal apnea because fetal breathing movements lead to upward and downward displacement of the heart and the ductus arteriosus. Once an image was obtained, it was electronically enlarged and printed on A4-size videoprint-paper. A line was drawn through that part of the ductus arteriosus where it appears to follow an approximately longitudinal course. A second line was drawn through the upper part of the thoracic vertebral column opposite the cardiac outflow tract. Measuring downstream (caudally) the angle between these two lines was determined. d) Colour flow velocity imaging (Fig. 4)

Nineteen normally developing fetuses between 14 and 25 weeks menstrual age recruited from the same group as those described in c) were examined with a Philips $P 700$ real-time and colour velocity imaging (CVI) scanner with a $3.5 \mathrm{MHz}$ transducer. The high axial resolution of CVI makes it possible to differentiate between velocities within a particular vessel using a highly developed form of B-mode ultrasound. Instead of depicting waveform patterns, maximum velocities within a given area are depicted with a colour code on what otherwise is a B-mode image. Once a satisfactory image of the short-axis view as described above was obtained, the colour option was activated. From 14 weeks onwards, it was possible to differentiate between the ductus arteriosus and the aortic arch. We then proceeded to use the CVI colour code to locate the point of highest blood flow velocity inside the ductus arteriosus. Colour prints were made on a SONY Mavigraph colour printer. For the purpose of angle determination, a line was drawn through the ductus arteriosus and the thoracic part of the fetal vertebral column.

\section{RESULTS}

\section{a) Microscopic reconstructions}

The upstream angle varied between $30^{\circ}$ and $80^{\circ}$ (mean $60.90^{\circ}, \mathrm{SD} 13.93^{\circ}$ ) and the downstream angle ranged between $80^{\circ}$ and $120^{\circ}$ (mean $106.5^{\circ}$, SD $14.15^{\circ}$ ). There was no statistically significant relationship with menstrual age: $\mathrm{R}$-value for the upstream angle was +0.07 and for the downstream angle +0.15 .

\section{b) Macroscopic study of fetuses}

The upstream angle varied between $45^{\circ}$ and $80^{\circ}$ (mean $61.87^{\circ}$, SD $10.66^{\circ}$ ) and the downstream angle ranged between $90^{\circ}$ and $115^{\circ}$ (mean $99.37^{\circ}$, SD $7.28^{\circ}$ ). There was no statistically significant relationship with menstrual age, the R-value for the upstream angle being -0.56 and for the downstream angle +0.40 . The mean angle between the ductus arteriosus and the thoracic spine was $88.33^{\circ}$ (SD $4.08^{\circ}$ ).

\section{c) Ultrasound images}

The angle between the ductus arteriosus and the thoracic spine ranged between $85^{\circ}$ and $115^{\circ}$ (mean $\left.93.26^{\circ}, \mathrm{SD} 6.09^{\circ}\right)$. There was no statistically significant relationship with menstrual age as shown by an $R$ value of +0.07 .

\section{d) CVI registrations}

Blood velocities increased as blood passed from the pulmonary trunk into the ductus arteriosus. Blood in the ductus always displayed a different colour-code, 


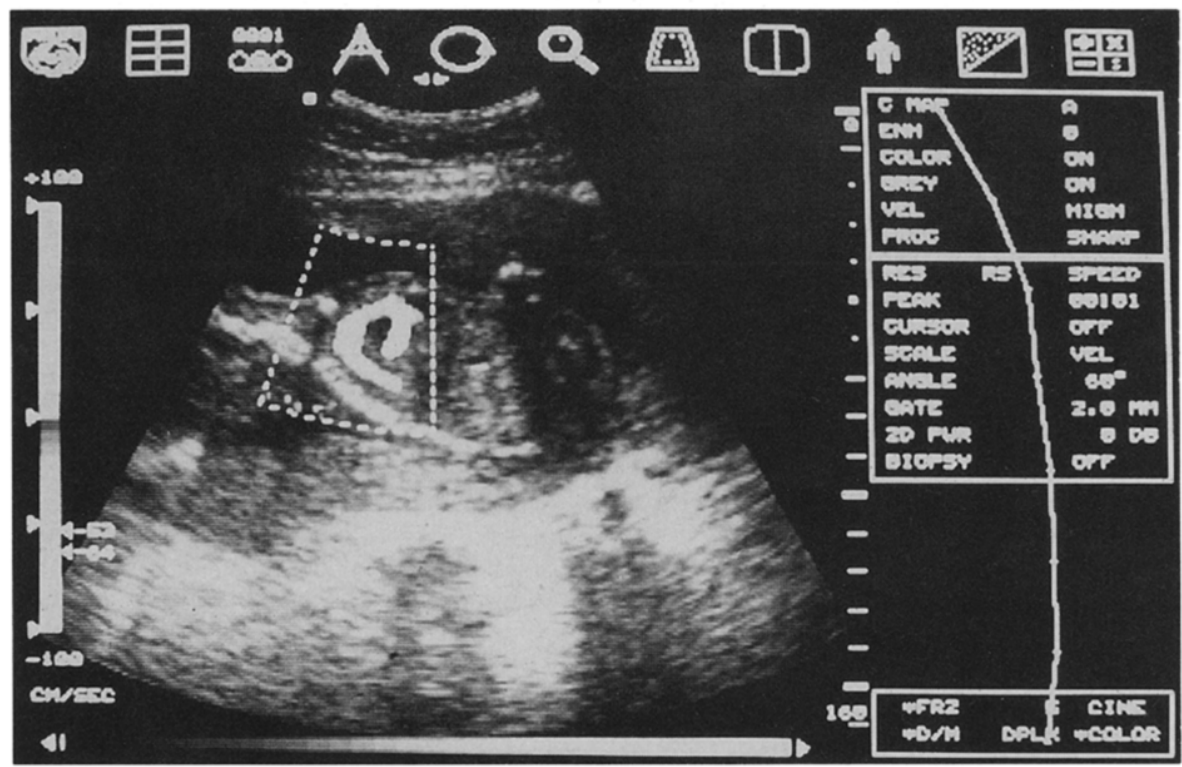

Fig. 4. Black and white reproduction of a CVI image of the right cardiac outflow tract of a healthy fetus of 20 weeks of gestation. Blood flow is depicted in white. The curved nature of the pulmonary trunk/ductus arteriosus part of the right cardiac outflow tract is clearly visible.

signifying a higher velocity, than that in the pulmonary trunk. Highest overall velocities inside the ductal lumen were shown to be near the inferior surface of the ductus arteriosus at the point of insertion into the aorta, i.e., blood on the "inside track" of the slightly curved vessel displayed the highest flow velocities. Measurements of the angle between the ductus and the thoracic spine resulted in data ranging from $85^{\circ}$ to $100^{\circ}$ (mean $90.26^{\circ}$; SD $3.52^{\circ}$ ); no statistically significant relationship with menstrual age was observed, the R-value being -0.30 .

\section{DISCUSSION}

Proper angling is essential for sonographic ductal velocity measurements. The smaller the interrogation angle between Doppler ultrasound beam and ductal flow direction, the more accurate will be the absolute velocities measured inside this vessel.

In the anatomical part of the study, the upstream angle between the ductus arteriosus and the aortic isthmus was always less than $90^{\circ}$, and the downstream angle between the ductus arteriosus and the descending aorta always $80^{\circ}$ or more. There was, however, a wide distribution of data. The angle between the ductus arteriosus and thoracic spine was more consistent, at approximately $90^{\circ}$. In both the micro-preparations and macro-preparations none of these angles changed significantly with menstrual age.

Interest in the spatial relationship between the fetal ductus arteriosus and surrounding vessels, in partic- ular the aorta, has been expressed in several reports with emphasis on both the upstream angle (Roeder 1902; Mancini 1951) and downstream angle (Faber 1912; Odé 1951). A specific angle between the ductus and aorta was thought to be instrumental in ductal closure. Strassmann (1894) believed that due to the acute angle with which the ductus inserted in the aorta, a thin wedge of tissue at the upper part of the insertion would be pushed into the ductal orifice after birth under the pressure of increased blood flow through the aortic arch, and thus effect ductal closure. Based on in situ measurements of mature newborns Roeder (1902) stated that the (upstream) angle between the ductus arteriosus and the aortic arch was $33^{\circ}$. He stressed the importance of the acute angle in the prevention of turbulent flow at the point of aortic insertion of the ductus. In a series of postmortem studies on premature and full term infants, upstream angles ranged between $25^{\circ}$ and $37.5^{\circ}$ (Mancini 1951). This is considerably smaller than that observed in the present study, which may be due to the difference in menstrual age between both studies. More in agreement with the present study, downstream measurements after birth have been reported with angles of approximately $90^{\circ}$ and a pointing downwards of the ductal orifice into the aortic lumen (Faber 1912). Odé (1951), performing downstream measurements, was the first to measure angles in very early gestation (fetal crown rump length $10 \mathrm{~mm}$ ) and ending with mature newborns. Early in gestation, an angle of $85^{\circ}$ was established that increased to $140^{\circ}$ at 24 weeks and decreased to $100^{\circ}$ at term. 
In the present study, we have tried to correlate postmortem findings in preserved fetuses with in vivo ultrasound images. There is no way of establishing the position of the heart inside the thorax at the time the preserved fetuses expired. During fetal breathing movements, the heart moves upwards and downwards with the diaphragm and as a result the direction of the ductus arteriosus changes. Agonal changes like contractions of the diaphragm but also fixation procedures (Hörnblad and Larsson 1967; Meurs van Woezik and Klein 1974) may lead to the heart, the ductus arteriosus and the aortic arch being preserved in a displaced position. A further problem arises from the fact that angles are a linear geometrical concept, whereas the ductus arteriosus together with the pulmonary trunk represent a slightly arched structure similar to the aortic arch with which it eventually converges. Moreover, the arch described by the aortic arch is not necessarily completed at the point of ductal insertion: when the ductus arteriosus inserts higher into the aortic arch, the immediate downstream part of the descending aorta will be a continuation of the arch over a few millimeters, and only then becomes the straight vessel that runs parallel to the oesophagus (Fig. 1b). It might be argued that angle determination in arched structures should not be attempted at all because of these pitfalls. However, describing the spatial relationship between two eliptically arched tubes that fuse into each other necessitates extensive mathematical calculations that can not be applied in clinical practice. Angle determination still has a place, and correct angle assessment is of paramount importance in Doppler ultrasound.

One of the aims of the present study was to determine whether sonographers measuring fetal ductal flow velocities would have to take into account menstrual age dependent changes in the spatial relationship between the ductus arteriosus and the aorta.

Our macro-anatomical and micro-anatomical data as well as our in vivo results from real-time and CVI ultrasound studies, show that during the late first and second and early third trimester of pregnancy menstrual age dependent angle adjustments appear not to be necessary when performing ductal flow velocity measurements.

Acknowledgement-C. B. is supported by grant JO-602/med of the Austrian Science Foundation.

\section{REFERENCES}

Allan, L. D.; Crawford, D. C.; Anderson, R. H.; Tynan, M. J. Echocardiographic and anatomical correlations in fetal congenital heart disease. Br. Heart J. 53:542-548; 1984.
Angelini, A.; Allan, L. D.; Anderson, R. H.; Crawford, D. C.; Chita, S. K.; Ho, S. Y. Measurements of the dimensions of the aortic and pulmonary pathways in the human fetus: A correlative echocardiographic and morphometric study. Br. Heart J. 60:221-226; 1988.

Brezinka, C.; Huisman, T. W. A.; Stijnen, T.; Wladimiroff, J. W. Normal Doppler flow velocity waveforms in the fetal ductus arteriosus in the first half of pregnancy. Ultrasound Obstet. Gynecol. 2:397-401; 1992.

Clyman, R. I.; Saugstad, O. D.; Mauray, F. Reactive oxygen metabolites relax the lamb ductus arteriosus by stimulating prostaglandin production. Circ. Res. 64:1-8; 1989.

Coceani, F.; Kelsey, L. Endothelin-1 release from lamb ductus arteriosus: Relevance to postnatal closure of the vessel. Can. J. Physiol. Pharmacol. 69:218-221; 1991.

Congdon, E. D. Transformation of the aortic arch system during the development of the human embryo. Contrib. Embr. Carnegie Instit. Washington 14:47-110;1922.

DeRuiter, M. C.; Gittenberger-de Groot, A. C.; Rammos, S.; Poelmann, R. E. The special status of the pulmonary arch artery in the branchial arch system of the rat. Anat. Embryol. 179:319325; 1989.

Faber, A. Die anatomischen und physikalischen Verhältnisse des Ductus Botalli. Arch. Anat. Entwgesch. 157-170; 1912.

Gittenberger-de Groot, A. C.; Van Ertbruggen, I.; Moulaert, A. J., Harinck, E. The ductus arteriosus in the preterm infant: Histologic and clinical observations. J. Pediatr. 96:88-93; 1980.

Groenenberg, I. A. L.; Hop, W. C. J.; Wladimiroff, J. W. Fetal cardiac and peripheral arterial flow velocity waveforms in intrauterine growth retardation. Circulation 80:1711-1717; 1989.

Hörnblad, P. Y.; Larsson, K. S. Studies on closure of the ductus arteriosus. I. Whole-body freezing as improvement of fixation procedure. Cardiologia 51:231-241; 1967.

Huhta, J. C.; Moise, K. J.; Fisher, D. J.; Sharif, D. S.; Wasserstrum, N.; Martin, C. Detection and quantitation of constriction of the fetal ductus arteriosus by Doppler echocardiography. Circulation 75:406-412; 1987.

Huisman, T. W. A.; Wladimiroff, J. W. Colour velocity imaging (CVI) in evaluation of the fetal circulation. Medicamundi 37:39; 1992.

Mancini, A. J. A study of the angle formed by the ductus arteriosus with the descending aorta. Anat. Rec. 109:535-539; 1951.

Meurs van Woezik, H.; Klein, H. W. Calibres of aorta and pulmonary artery in hypoplastic left and right heart syndrome: Effects of abnormal bloodflow? Virchows Arch. A. Path. Anat. and Histol. $364: 357-364 ; 1974$.

Moise Jr, K. J.; Huhta, J. C.; Sharif, D. S.; Ou, C. N.; Kirshow, B.; Wasserstrum, N.; Lorraine, C. Indomethacin in the treatment of premature labor. Effects on the ductus arteriosus. N. Engl. J. Med. 319:327-331; 1988.

Odé, E. De ductus arteriosus. Thesis, University of Leiden, The Netherlands; 1951.

Olley, P. M.; Coceani, F. Lipid mediators in the control of the ductus arteriosus. Am. Rev. Respir. Dis. 136:218-219; 1987.

Pesque, P. Colour Velocity Imaging: A technology that bypasses Doppler and measures blood flow directly. Hospimedica 8:1-4; 1990.

Reed, K. L.; Anderson, C. F.; Shenker, L. Ductal arch. In: Fetal echocardiography — An atlas. New York: Alan R. Liss; 1988:3742 .

Roeder, H. Die Histogenese der arteriellen Gänge. Arch. Kinderheilkd. 33:147-161; 1902.

Strassman, P. Anatomische und physiologische Untersuchungen über den Blutkreislauf beim Neugeborenen. Arch. Gyn. 45:393$445 ; 1894$.

Tinkelenberg, J. A graphic reconstruction: Microanatomy with a pencil. J. Audiovis. Media Med. 2:102-106; 1979. 